\title{
The Chemical Basis for the Electrical Stratigraphy of Ice
}

\author{
JOHN C. MOORE AND ERIC W. WOLFF
}

\author{
British Antarctic Survey, Natural Environment Research Council, Cambridge, United Kingdom \\ HeNrik B. Clausen and Claus U. Hammer \\ Geophysical Isotope Laboratory, University of Copenhagen, Denmark
}

\begin{abstract}
Antarctic and Greenland ice core samples were studied using two different stratigraphic electrical techniques. The electrical conductivity measurement (ECM) technique is a dc method, while dielectric profiling (DEP) is an ac method. It was found that ECM responds only to acid, even in large excess of neutral salt concentrations. DEP responds to both acid and salt content of the ice. Acids may be giving rise to conduction through an increase in the number of ionisation defects, or through a network of liquid veins between ice grains. Salts on the other hand appear to give rise to Bjerrum defects, which are bound charges and cannot provide a dc current, but do produce a dielectric ac conductivity. The two methods can be used together to give a rapid prediction of both acid and salt content of cores. This may be of particular use in Wisconsin-age ice from Greenland, but can generally be used to define parts of cores worthy of detailed chemical study.
\end{abstract}

\section{INTRODUCTION}

There have been numerous studies of the electrical properties of pure, laboratory-grown ice [Hobbs, 1974]. Natural ice from the polar ice sheets contains small quantities $(\approx \mu \mathrm{M})$ of soluble impurities. These consist chiefly of marine ions $\left(\mathrm{Na}^{+}, \mathrm{Mg}^{2+}, \mathrm{Cl}^{-}\right.$, $\mathrm{SO}_{4}{ }^{2-}$, etc.), sulphuric and nitric acids, $\mathrm{H}_{2} \mathrm{O}_{2}$, and lesser amounts of organic acids and soluble terrestrial material. Trace levels of impurity in ice grown from dilute solutions have been shown to affect the dielectric behaviour [Camplin et al., 1978; Gross et al., 1978; Takei and Maeno, 1987]. However, it is only in recent years that it has been realised that chemical impurities dominate the electrical properties of natural ice from the polar regions.

Two stratigraphic electrical techniques have been developed for use on solid polar ice; these both measure variations in the electrical properties of the ice in order to assess rapidly the chemical stratigraphy of the ice. The electrical conductivity measurement (ECM) developed by Hammer [1980] is essentially a dc method, and has been used as an indicator of the acidity of the ice, particularly to define volcanic reference horizons. The dielectric profiling technique (DEP) developed by Moore and Paren [1987] is an ac method, and the derived parameters have been shown to depend both on the acid and salt (marine ion) content of the ice [Moore et al., 1989].

In this study, the two electrical methods are used together for the first time. Detailed ECM, DEP and chemical measurements have been made of two sections of ice from Antarctica and Greenland. The data are analyzed to define more clearly the chemical factors that determine the electrical properties of polar ice. The potential of the two methods used together to give a highly resolved picture of the chemical variations in an ice core is demonstrated. Some implications of the results for electrical conduction mechanisms in polar ice are also discussed.

\section{SAMPLES}

Antarctic samples were from the core drilled at Dolleman Island $\left(70^{\circ} 35^{\prime} \mathrm{S}, 60^{\circ} 55^{\prime} \mathrm{W}\right.$, elevation $400 \mathrm{~m}$, mean annual

Copyright 1992 by the American Geophysical Union.

Paper number $91 \mathrm{JB} 02750$. 0148-0227/92/91JB-02750\$05.00 temperature $-17^{\circ} \mathrm{C}$, average accumulation over 200 years $\approx 0.38 \mathrm{~m}$ ice/year) in the Antarctic Peninsula. Chemical and DEP measurements made previously on sections of this core have been described elsewhere [Mulvaney and Peel, 1988; Moore et al., 1989]. Dolleman Island is a coastal site that exhibits high concentrations of marine ions, with mean $\mathrm{Na}^{+}$values above 10 $\mu \mathrm{M}$, and peak $\mathrm{Na}^{+}$concentrations above $100 \mu \mathrm{M}$. The chemistry contrasts with that of cores from central Antarctica, where, as at South Pole, $\mathrm{Na}^{+}$may average at less than $1 \mu \mathrm{M}$ [Legrand and Delmas, 1984]. The core also shows strong peaks in sulphate, in excess of that attributable to sea salt, and these are associated with high $\mathrm{H}^{+}$contents. The acidic sulphate is believed to be produced mainly by photochemical oxidation of biogenically derived sulphur gases, and it peaks in summer (based on dating by cycles of oxygen isotope ratios in the ice). The marine ions tend to peak in the autumn/winter period. The existence of a wide range of impurity concentrations, and of strong peaks in both acid and marine ions, separated in depth, makes this a particularly useful core for the study of the effect of chemistry on the electrical properties of the ice.

For this study, a $2.56 \mathrm{~m}$ length of core (88.09-90.65 m depth in the core) was chosen. The section has an estimated age of about 200 years. After drilling, it had been maintained in a cold store at $-20^{\circ} \mathrm{C}$.

Greenland samples came from a core drilled at Site G $\left(71^{\circ} 09^{\prime} \mathrm{S}, 35^{\circ} 50^{\prime} \mathrm{W}\right.$, elevation $3098 \mathrm{~m}$, mean annual temperature $30.1^{\circ} \mathrm{C}$, recent accumulation rate $0.251 \mathrm{~m}$ of ice/year) in central Greenland. Aspects of the core chemistry have been discussed elsewhere [Clausen et al., 1988; Clausen and Hammer, 1988]. A $1.10 \mathrm{~m}$ section of core (68.75 - $69.85 \mathrm{~m}$ depth) was chosen. Using a combination of stratigraphic dating (oxygen isotope ratios) and fixed reference horizons, this section had previously been shown to cover the years 1782-1785 AD, and therefore includes the acid peak corresponding to the eruption of the volcano of Laki in 1783. Clausen and Hammer [1988] have already presented the ECM data for this section of core.

\section{METHODS}

\section{ECM}

In the ECM technique [Hammer, 1980], a microtome knife is used to prepare a fresh, flat surface along the length of the core. 
Some samples seem to "age" with storage [Maccagnan et al., 1981; Schwander et al., 1983], so that a few mm must be removed to obtain a full-strength response from ECM. A pair of brass electrodes $\left(\approx 1.5 \mathrm{~mm}^{2}\right.$ in area, $\approx 1 \mathrm{~cm}$ apart) are run along the ice surface at a speed of a few $\mathrm{cm} / \mathrm{s}$ while a high voltage $(1250 \mathrm{~V})$ is applied across the electrodes. The current $(\approx \mu \mathrm{A})$ flowing between the electrodes is recorded, and has traditionally been converted into acidity using previously obtained calibration curves [Hammer, 1980]. Naturally, the calibration will depend on the precise characteristics of the electrodes and the technique of the operator (through angle of electrodes, pressure and speed of movement along the ice). For this study, measurements were carried out by an experienced operator in a cold room at $\approx-14^{\circ} \mathrm{C}$. Continuously recorded data were digitized in $1 \mathrm{~cm}$ intervals, and were corrected to a standard temperature of $-14^{\circ} \mathrm{C}$ using an activation energy of $0.23 \mathrm{eV}\left(22 \mathrm{~kJ} \mathrm{~mol}^{-1}\right)$ [Hammer, 1983].

It should be noted that the ECM is not a direct measure of electrical conductivity. However, it has been shown [Schwander et al., 1983] that, as used, volume conduction dominates over surface conduction, and the current is therefore closely related to the conductivity of the ice.

\section{DEP}

In contrast to ECM, the DEP technique requires no special ice surface preparation, and no physical contact between the electrodes and ice is necessary. The core is kept in pristine condition within a polyethylene sleeve, and is placed within a set of curved, segmented electrodes [Moore and Paren, 1987]. DEP is totally nondestructive, and repeatable measurements are made with an applied voltage of $1 \mathrm{~V}$. The dielectric response of the core is determined using a microprocessor-controlled bridge sweeping the AF-LF frequency range. By switching electrode segments on in succession, a profile along the core of dielectric properties is obtained. The DEP system used here has a resolution of $5 \mathrm{~cm}$, though this can be improved upon. However, the geometry of the DEP method means that the resolution of DEP is inherently limited compared to that of ECM. As set up here with 42 frequencies between $20 \mathrm{~Hz}$ and $300 \mathrm{kHz}$ measured at each electrode segment, about 20 mins is required to analyze a meter of core. Both the Dolleman Island and Site G cores were $104 \pm 2 \mathrm{~mm}$ in diameter, both were measured within a polyethylene sleeve $0.125 \mathrm{~mm}$ thick.

Raw DEP data consist of capacitance and conductance measurements at a range of frequencies that span the main dielectric dispersion of ice [Hobbs, 1974]. The data were modelled by two or three dielectric dispersions, the highest frequency range (dominant above a few $\mathrm{kHz}$ ) being the main dispersion. Two dielectric parameters, of the many that can be used to summarize the raw DEP data, have been found to be good indicators of the chemical composition of ice [Moore et al., 1989]. These parameters are the high frequency limiting conductivity, $\sigma_{\infty}$, and the relaxation frequency, $f_{r}$ of the dominant dispersion of the ice/polyethylene dielectric. These two parameters clearly depend both on the acid and marine ion content of the ice [Moore et al., 1989]. The conductivity $\sigma_{\infty}$ is the sum of two components, the dc conductivity of the ice in series with the polyethylene sleeve producing a low frequency dielectric dispersion, and the dielectric loss conductivity of the ice produced by Bjerrum charges.

For this study, DEP measurements were carried out in a cold room at $-22^{\circ} \mathrm{C}$. Two segmented electrodes were switched on at any time, so that each measurement sampled $10 \mathrm{~cm}$ of ice, with a $5 \mathrm{~cm}$ shift along the core between samples.

\section{Chemical Measurements}

Parts of the Dolleman Island cores were cut and analyzed in Copenhagen and Cambridge (Table 1). In Cambridge, cutting intervals (after removal of the outside of cores) were devised to give the maximum resolution in the most interesting parts of the core. All 104 samples were analyzed for $\mathrm{Cl}^{-}, \mathrm{NO}_{3}{ }^{-}$and $\mathrm{SO}_{4}{ }^{2-}$ by ion chromatography (precision better than $10 \%$ ). For $\mathrm{Na}^{+}$and $\mathrm{Mg}^{2+}$, analysis was by flame atomic absorption spectrometry (AAS), and for $\mathrm{K}^{+}$by flame emission. Precautions were taken to ensure that all samples after melting had fully equilibrated to room temperature, since sample temperature grossly affects sample uptake (through viscosity) into the flame, and hence sensitivity. In addition, it was found that sensitivity varied greatly between different samples, and between samples and standards (which were lightly acidified), because of the ionisation interference mechanism. This was overcome by acidifying aliquots of all samples with $100 \mu \mathrm{M} \mathrm{HCl}$ before cation analysis. Precision was about $3 \%$ for these analyses. $\mathrm{Ca}^{2+}$ was analyzed by graphite furnace AAS (precision $\approx 5 \%$ ). $\mathrm{H}^{+}$analysis was by acid titration [Mulvaney and Peel, 1988; Legrand et al., 1982], with an estimated precision of $0.3 \mu \mathrm{M}$.

Anions were analyzed in Copenhagen by ion chromatography. $\mathrm{H}^{+}$was calculated by measuring $\mathrm{pH}$ of melted samples and correcting the values for $\mathrm{CO}_{2}$ uptake by standards. Dust content was measured by a laser scattering method [Hammer et al., 1985].

The core section from Site G, Greenland was cut into $2.5 \mathrm{~cm}$ slices in Cambridge, and analyzed there for $\mathrm{H}^{+}, \mathrm{Na}^{+}, \mathrm{Mg}^{2+}, \mathrm{Cl}^{-}$, $\mathrm{NO}_{3}{ }^{-}$, and $\mathrm{SO}_{4}{ }^{2-}$. For $\mathrm{H}^{+}$alone between 68.75 and $69.25 \mathrm{~m}$, adjacent samples were pooled due to low sample volumes, giving a $5 \mathrm{~cm}$ resolution. In Copenhagen, only $\delta^{18} \mathrm{O}$ analyses were carried out on melted portions of these samples at $4 \mathrm{~cm}$ resolution.

\section{RESUlts}

Chemical data obtained in Cambridge for the Dolleman Island samples are shown in Figure 1. The major feature in the profiles for marine ions is the huge peak at $89.6 \mathrm{~m}$. This is in fact the largest $\mathrm{Na}^{+}$peak in the Dolleman Island core. As with many of the larger $\mathrm{Na}^{+}$peaks in the core, the marine ion ratios in the samples at and around the peak depart from those of seawater. This is being investigated but is not the subject of this paper. As expected from the rest of the core, sulphate and $\mathrm{H}^{+}$show a regular seasonal variation. $\mathrm{H}^{+}$actually goes to zero at the $\mathrm{Na}^{+}$ peak. In the sections where dust analyses were made, the average dust content was $16 \mu \mathrm{g} \mathrm{kg}^{-1}$, with below-average values across the $\mathrm{Na}^{+}$peak.

There is an excellent ion balance (calculated in $\mu$ eq $\mathrm{L}^{-1}$ ) between cations and anions for all samples: the total of anions in the core is just $3 \%$ higher than total cations. Where the same analyses were carried out in Cambridge and Copenhagen, there is good agreement between the data. Figure 2 shows the profiles obtained by the two groups for $\mathrm{SO}_{4}{ }^{2-}$ and for $\mathrm{H}^{+}$. The result for $\mathrm{H}^{+}$is particularly pleasing since Cambridge used the acid titration method, which directly measures strong acidity only, while Copenhagen measured $\mathrm{pH}$ and then corrected for absorption of $\mathrm{CO}_{2}$. Agreement between the two methods breaks down only for the few samples where acid titration indicates a very low acidity $(0-2 \mu \mathrm{M})$, whereas the corrected $p \mathrm{H}$ measurements give acidities always at or above $2 \mu \mathrm{M}$. Since the low values coincide with areas where the ECM current fell to zero, we tend to believe the acid titration data. This suggests that the greater speed and convenience of $p \mathrm{H}$ measurements compared to the time- 
TABLE 1. Chemical Analyses of Dolleman Island Core

\begin{tabular}{|c|c|c|c|c|}
\hline \multirow[b]{2}{*}{ Depth, $m$} & \multicolumn{2}{|c|}{ Cambridge } & \multicolumn{2}{|c|}{ Copenhagen } \\
\hline & Interval, $\mathrm{cm}$ & Analyses & Interval, $\mathrm{cm}$ & Analyses \\
\hline $88.09-89.33$ & 3.0 & $\mathrm{Na}^{+}, \mathrm{Mg}^{2+}, \mathrm{K}^{+}, \mathrm{H}^{+}$ & & \\
\hline $89.33-89.41$ & 3.0 & $\begin{array}{l}\mathrm{Na}^{+}, \mathrm{Mg}^{2+}, \mathrm{K}^{+}, \mathrm{Ca}^{2+}, \\
\mathrm{H}^{+}, \mathrm{Cl}^{-}, \mathrm{NO}_{3}^{-}, \mathrm{SO}_{4}^{2-}\end{array}$ & & \\
\hline $89.41-89.80$ & 1.25 & $\begin{array}{l}\mathrm{Na}^{+}, \mathrm{Mg}^{2+}, \mathrm{K}^{+}, \mathrm{Ca}^{2+}, \\
\mathrm{H}^{+*}, \mathrm{Cl}^{-}, \mathrm{NO}_{3}, \mathrm{SO}_{4}{ }^{2-}\end{array}$ & 2.5 & $\begin{array}{l}\delta^{18} \mathrm{O}, \text { dust, } \mathrm{H}^{+} \\
\mathrm{Cl}^{-}, \mathrm{NO}_{3}{ }^{-}, \mathrm{SO}_{4}{ }^{2-}\end{array}$ \\
\hline $89.80-90.30$ & 2.5 & $\begin{array}{l}\mathrm{Na}^{+}, \mathrm{Mg}^{2+}, \mathrm{K}^{+}, \mathrm{H}^{+} \\
\mathrm{Cl}^{-}, \mathrm{NO}_{3}{ }^{-}, \mathrm{SO}_{4}{ }^{2-}\end{array}$ & 2.5 & $\begin{array}{l}\delta^{18} \mathrm{O}, \text { dust, } \mathrm{H}^{+} \\
\mathrm{Cl}^{-}, \mathrm{NO}_{3}{ }^{-}, \mathrm{SO}_{4}{ }^{2-}\end{array}$ \\
\hline $90.30-90.65$ & 3.0 & $\begin{array}{l}\mathrm{Na}^{+}, \mathrm{Mg}^{2+}, \mathrm{K}^{+}, \mathrm{H}^{+} \\
\mathrm{Cl}^{-}, \mathrm{NO}_{3}{ }^{-}, \mathrm{SO}_{4}{ }^{2-}\end{array}$ & & \\
\hline
\end{tabular}

* Due to low sample volumes available, adjacent samples were pooled to give $2.5 \mathrm{~cm}$ resolution for $\mathrm{H}^{+}$analyses alone in this section.

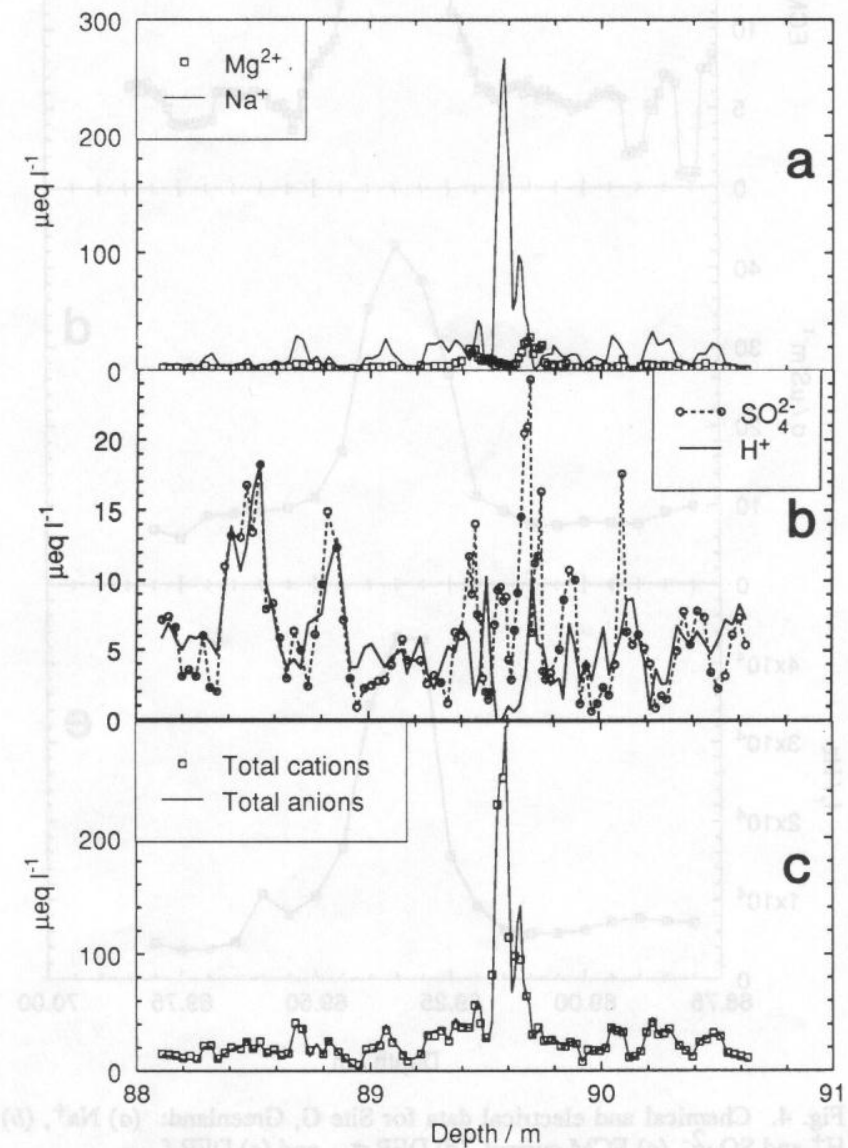

Fig. 1. Chemistry of the Dolleman Island core: (a) $\mathrm{Na}^{+}$and $\mathrm{Mg}^{2+},(b) \mathrm{H}^{+}$ and $\mathrm{SO}_{4}{ }^{2-}$, and $(c)$ total cations and total anions.

consuming acid titration technique must be traded for a slight loss of accuracy at low $\mathrm{H}^{+}$concentrations.

Dolleman ECM currents, DEP $\sigma_{\infty}$ and DEP $f_{r}$ are presented in Figure 3. The ECM current (ECM $I$ ) shows large variations, with

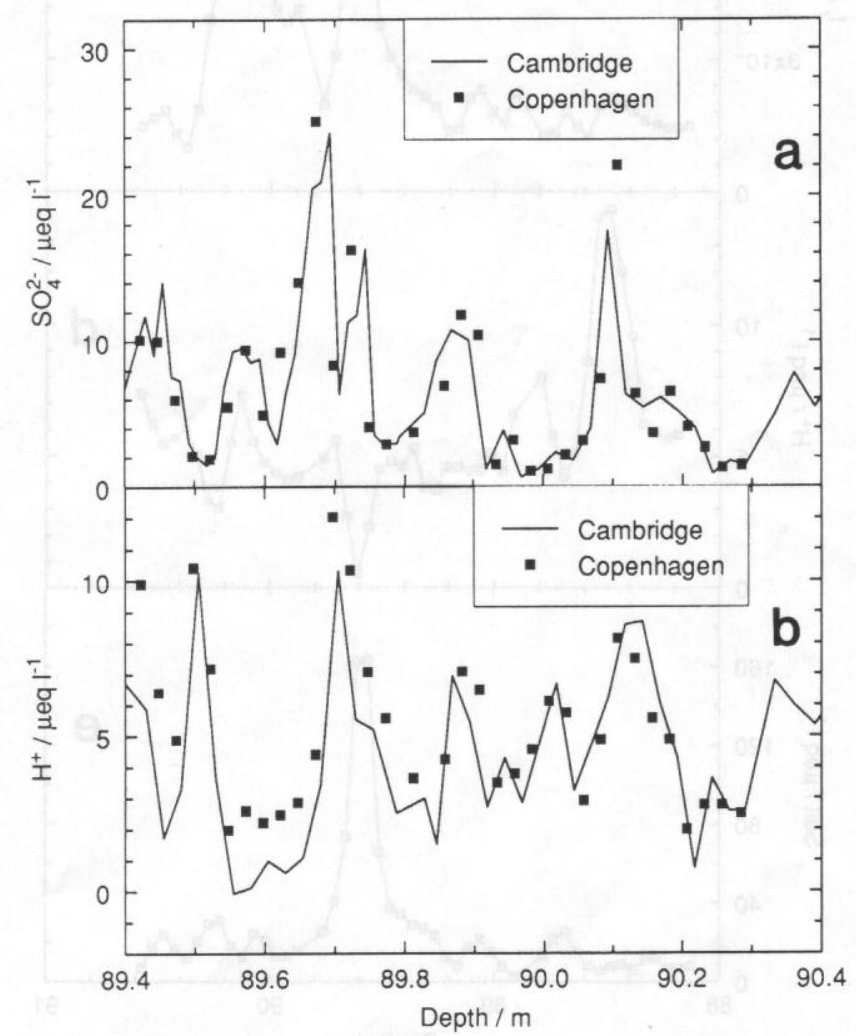

Fig. 2. Comparison of chemical measurements made on the Dolleman Island core in Copenhagen and Cambridge: (a) $\mathrm{SO}_{4}{ }^{2-}$ and $(b) \mathrm{H}^{+}$ measured by acid titration in Cambridge, via $\mathrm{pH}$ in Copenhagen.

several peaks as large as those seen at other sites for major volcanic eruptions, and with one section where the current fell to $<1 \mu \mathrm{A}$, a value generally seen only in alkaline ice from the Wisconsin period in Greenland.

The DEP data are less well resolved than other data, but show several features, particularly a large peak at $89.6 \mathrm{~m}$ in both 


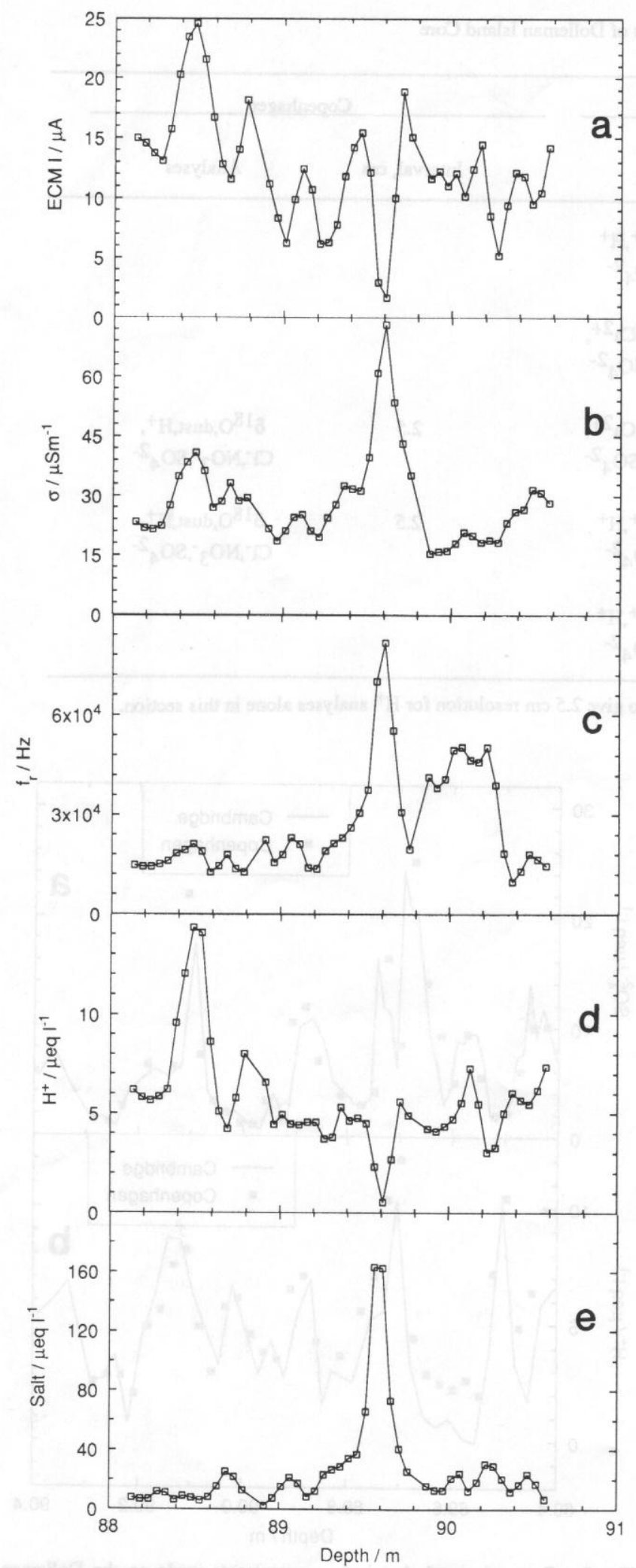

Fig. 3. Electrical and chemical parameters of the Dolleman Island core, all interpolated to depths of DEP analysis: (a) ECM current, (b) DEP $\sigma_{\infty}$, (c) DEP $f_{r},(d) \mathrm{H}^{+}$, and $(e)$ salt, as defined in the text.

parameters. The section from $89.81-90.65 \mathrm{~m}$ is unusual compared to the rest of the Dolleman core in that it contains ice where $\sigma_{\infty}$ is relatively low, but $f_{r}$ is high. Physical factors may account for this behavior; a bigger air gap between the ice and electrodes due to core diameter variations, or internal fractures in the ice would cause $f_{r}$ to rise while $\sigma_{\infty}$ remained low.

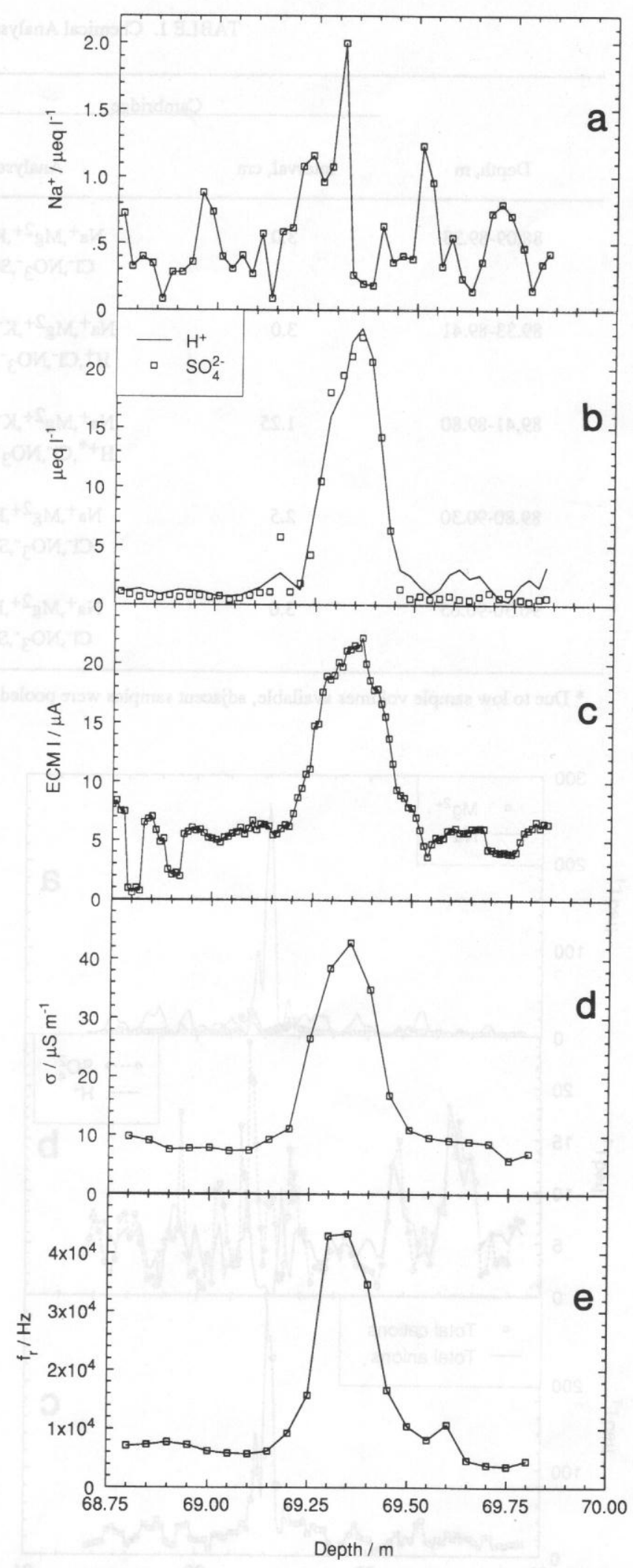

Fig. 4. Chemical and electrical data for Site G, Greenland: (a) $\mathrm{Na}^{+},(b)$ $\mathrm{H}^{+}$and $\mathrm{SO}_{4}{ }^{2-},(c)$ ECM current, (d) DEP $\sigma_{\infty}$, and $(e) \operatorname{DEP} f_{r}$.

The main chemical and electrical data for the Site $\mathbf{G}$ cores are shown in Figure 4. The data are straightforward, being dominated by one large peak in $\mathrm{H}^{+}, \mathrm{SO}_{4}^{2-}, \mathrm{ECM}$ current, and both DEP parameters. This is the volcanic acid peak corresponding to the 1783 Laki eruption [Clausen and Hammer, 1988]. $\mathrm{Na}^{+}$is always below $3 \mu \mathrm{M}$. 


\section{Electrical and CHEMical Parameters}

\section{Parameterization of the Variables}

The aim is to find the best relationships between the three electrical parameters and the simplest chemical parameters. Ideally, these parameters would be individual anion and cation concentrations. However, this was not feasible for several reasons. Analyzing all the available $45 \mathrm{~m}$ of Dolleman core we found no significant difference in the response of the DEP parameters to $\mathrm{Na}^{+}$and $\mathrm{Mg}^{2+}$. ECM is already believed to be insensitive to marine ion concentrations [Hammer, 1980; Maccagnan et al., 1981]. Therefore, for the statistical analyses, a composite neutral salt parameter called "salt" was used. This was calculated as the sum (in $\mu$ eq $\mathrm{L}^{-1}$ ) of $\mathrm{Na}^{+}, \mathrm{Mg}^{2+}, \mathrm{K}^{+}$and $\mathrm{Ca}^{2+}$; where either $\mathrm{Ca}^{2+}$ or $\mathrm{K}^{+}$were unavailable, "salt" was calculated from those cations that were available scaled up according to seawater ratios (a maximum factor of 1.05 where only $\mathrm{Na}^{+}$and $\mathrm{Mg}^{2+}$ were known). The salt parameter for the Dolleman core is shown in Figure 3.

In DEP, previous analyses [Moore et al., 1989] had calculated the concentration of strong acids as the sum of the anions not attributable to marine material (i.e. "excess" $\mathrm{Cl}^{-}+$"excess" $\mathrm{SO}_{4}{ }^{2-}$ $+\mathrm{NO}_{3}{ }^{-}$). In fact this would be difficult to calculate here because there are large departures of cations (and presumably anions) from seawater ratios for other reasons (this may have contributed some of the unexplained variance in previous DEP analyses). However, we have the more direct $\mathrm{H}^{+}$concentration available for use in this analysis.

There have been some suggestions that ECM currents may respond differently to the same quantities (in $\mu \mathrm{eq} \mathrm{L}^{-1}$ ) of acids associated with different anions [Zanolini, 1983; Wolff and Paren, 1984; Legrand et al., 1987], with $\mathrm{H}^{+}$as $\mathrm{H}_{2} \mathrm{SO}_{4}$ giving the lowest response. Because of the departures of ions from seawater ratios in the Dolleman core, it was difficult to assign acid to particular counter ions in this study, but it is clear that sulphate as a counter ion dominates the acid budget in both cores. It was therefore not found possible to draw any clear conclusions about the effect of different anions on the response of ECM to acid. A section of core with more equal concentrations of acidic $\mathrm{SO}_{4}{ }^{2-}, \mathrm{Cl}^{-}$, and $\mathrm{NO}_{3}{ }^{-}$is needed. Recent data from the Antarctic Byrd core (Hammer et al., paper in preparation, 1992) indicate that the ECM response from $\mathrm{HF}$ has the same calibration curve as that from $\mathrm{H}_{2} \mathrm{SO}_{4}, \mathrm{HCl}$ and $\mathrm{HNO}_{3}$.

The end result of these considerations is that five parameters are available for statistical analysis: $\mathrm{H}^{+}$, salt, $\operatorname{ECM} I, \sigma_{\infty}$, and $f_{r}$. To compare data from data sets with different sampling intervals, ECM data were interpolated to the chemical intervals, and chemical data were interpolated to DEP intervals. The interpolation was done by a simple averaging for the relevant coarse depth range. Naturally this interpolation has the effect of reducing the magnitude of some peaks from those in the raw data.

\section{ECM Calibration Curves}

It has previously been assumed that ECM responds only to acid [Maccagnan et al., 1981], though Hammer [1983] suggests that in alkaline ice, it is alkalinity that determines the current. From Figure 3, it is seen that the shape of the Dolleman ECM $I$ curve follows very closely that of $\mathrm{H}^{+}$as measured by acid titration, despite the existence of large marine ion concentrations. Indeed, over the peak where $\mathrm{Na}^{+}$is $>200 \mu \mathrm{M}$, but $\mathrm{H}^{+}$is close to zero, ECM current is $<1 \mu \mathrm{A}$. It is clear that neutral salts, even in vast excess, do not give rise to any ECM current; this may indicate that they play no role in the dc conductivity of polar ice cores.
In both cores, there is just one ECM feature that is not represented by a feature in the acid profile, and that is a peak at about $89.1 \mathrm{~m}$ at Dolleman Island. This section (about $14 \mathrm{~cm}$ long) was highly fractured because the core had been dropped; the peak is therefore probably an artifact.

Plots of ECM current versus $\mathrm{H}^{+}$are shown in Figure 5. For both cores, there is a definite relationship within a scattered data set. A wide range of functions would fit the data reasonably.

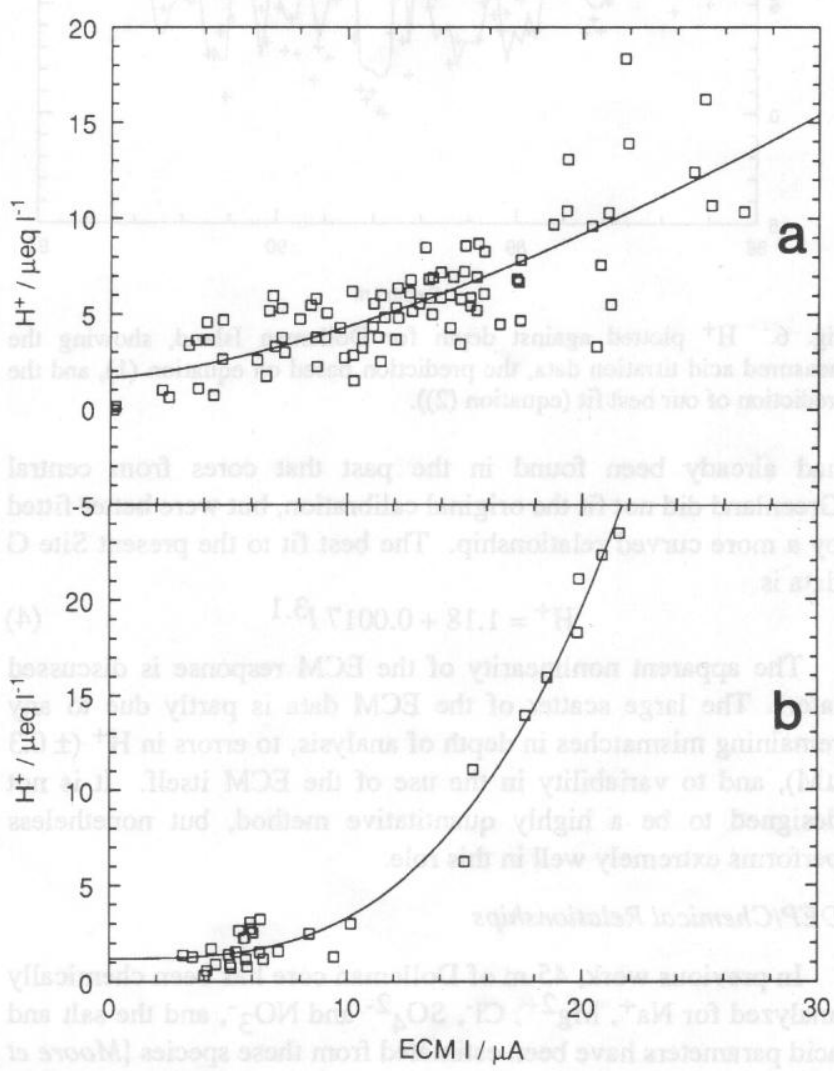

Fig. 5. $\mathrm{H}^{+}$versus ECM current, with the best fits obtained (equations (2) and (4)): (a) Dolleman Island and (b) Site G.

For the Dolleman data, the best fit by linear regression gives a correlation coefficient of 0.79 ( 88 points), but performs badly at low $\mathrm{H}^{+}$values; the data do appear nonlinear. An improved fit is obtained with a polynomial of the form $y=a+b x+c x^{2}$ or with a nonlinear equation of the form $y=a+b x^{n}$. Hammer [1980] used an equation of the latter form to obtain his original calibration of $\mathrm{H}^{+}$ on $I$. His equation

$$
\mathrm{H}^{+}=0.045 I^{1.73}
$$

( $I$ in $\mu \mathrm{A}, \mathrm{H}^{+}$in $\mu$ eq $\mathrm{kg}^{-1}$ ) gives a fair fit to the Dolleman data, but gives consistently low predictions of $\mathrm{H}^{+}$. The best fit of this form to the Dolleman data is

$$
\mathrm{H}^{+}=1.64+0.090 I^{1.48}
$$

This is a good fit (Figure 6) but does not allow for zero acidities, as it obviously should. The best fit of this form for $I$ on $\mathrm{H}^{+}$is

$$
I=-0.24+4.5 \mathrm{H}^{0.62}
$$

With the data available, we cannot choose between the various possible formulae. However, it is clear that ECM can reveal detailed trends (at resolutions of order $1 \mathrm{~cm}$ ), and small changes in acidity, even at low levels.

For Site G, plots of $I$ versus $\mathrm{H}^{+}$are clearly nonlinear, and the published formula [Hammer, 1980] is also a poor fit. However, it 


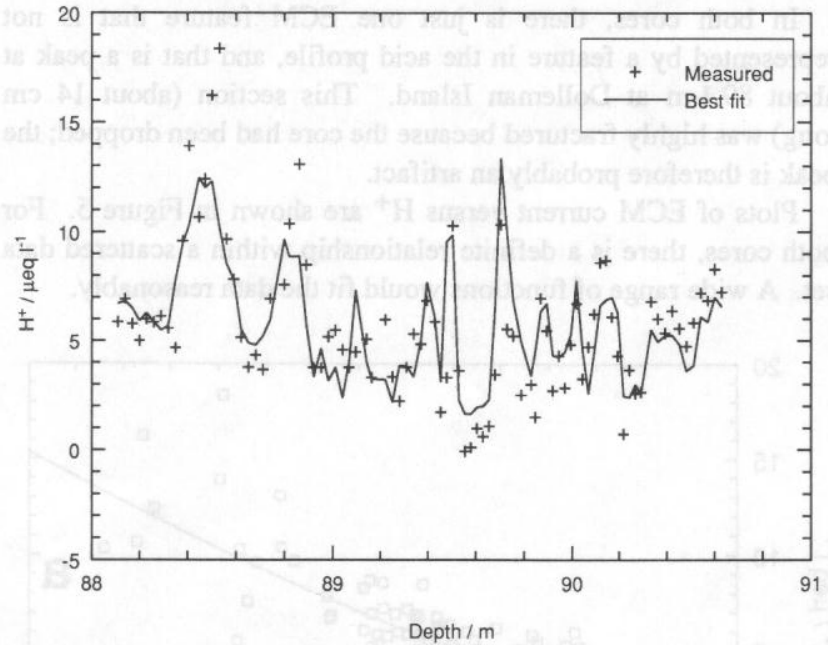

Fig. 6. $\mathrm{H}^{+}$plotted against depth for Dolleman Island, showing the measured acid titration data, the prediction based on equation (1), and the prediction of our best fit (equation (2)).

had already been found in the past that cores from central Greenland did not fit the original calibration, but were better fitted by a more curved relationship. The best fit to the present Site G data is

$$
\mathrm{H}^{+}=1.18+0.0017 I^{3.1}
$$

The apparent nonlinearity of the ECM response is discussed later. The large scatter of the ECM data is partly due to any remaining mismatches in depth of analysis, to errors in $\mathrm{H}^{+}( \pm 0.3$ $\mu \mathrm{M}$ ), and to variability in the use of the ECM itself. It is not designed to be a highly quantitative method, but nonetheless performs extremely well in this role.

\section{DEP/Chemical Relationships}

In previous work, $45 \mathrm{~m}$ of Dolleman core has been chemically analyzed for $\mathrm{Na}^{+}, \mathrm{Mg}^{2+}, \mathrm{Cl}^{-}, \mathrm{SO}_{4}{ }^{2-}$ and $\mathrm{NO}_{3}{ }^{-}$, and the salt and acid parameters have been estimated from these species [Moore et al., 1989]. Acid was calculated as

$$
[\text { acid }]=\left[\mathrm{Cl}^{-}\right]+\left[\mathrm{SO}_{4}{ }^{2-}\right]+\left[\mathrm{NO}_{3}^{-}\right]-[\text {salt }]
$$

The relationships found for the DEP variables at $-22^{\circ} \mathrm{C}$ were

$$
\begin{gathered}
\sigma_{\infty}=0.39( \pm 0.01)[\text { salt }]+1.43( \pm 0.05)[\text { acid }]+12.7( \pm 0.3) \\
f_{r}=440( \pm 10)[\text { salt }]+612( \pm 60)[\text { acid }]+8200( \pm 400)
\end{gathered}
$$

where the units of $\sigma_{\infty}$ are $\mu \mathrm{S} \mathrm{m} \mathrm{m}^{-1}, f_{r}$ is in $\mathrm{Hz}$, the chemical species are in $\mu \mathrm{eq} \mathrm{L}^{-1}$ and the values in brackets represent one standard deviation. In the present paper, $\mathrm{H}^{+}$measured directly is used instead of the acid parameter. For the Dolleman data these relationships provide good fits of the interpolated chemistry to the measured $\sigma_{\infty}$ and $f_{r}$ on the sections $88.09-89.80 \mathrm{~m}$ (Figure 7), and it is obvious that both acid and salt are contributing peaks to the $\sigma_{\infty}$ profile. It should be noted that equations (6) and (7) were found after a nonlinear regression analysis; the exponents for both salt and acid factors were very close $(0.99 \pm 0.05$ and $1.03 \pm 0.1$ for $\sigma_{\infty}$ ) to unity.

The section of Dolleman core from $89.80-90.65 \mathrm{~m}$, as was discussed earlier, is an unusual core, and neither equations (6) and (7) nor any reasonable nonlinear equation that is adequate for the majority of the core, provide a good fit to the data. For this reason, the data from this section will not be included in further discussion of the DEP statistical analysis.

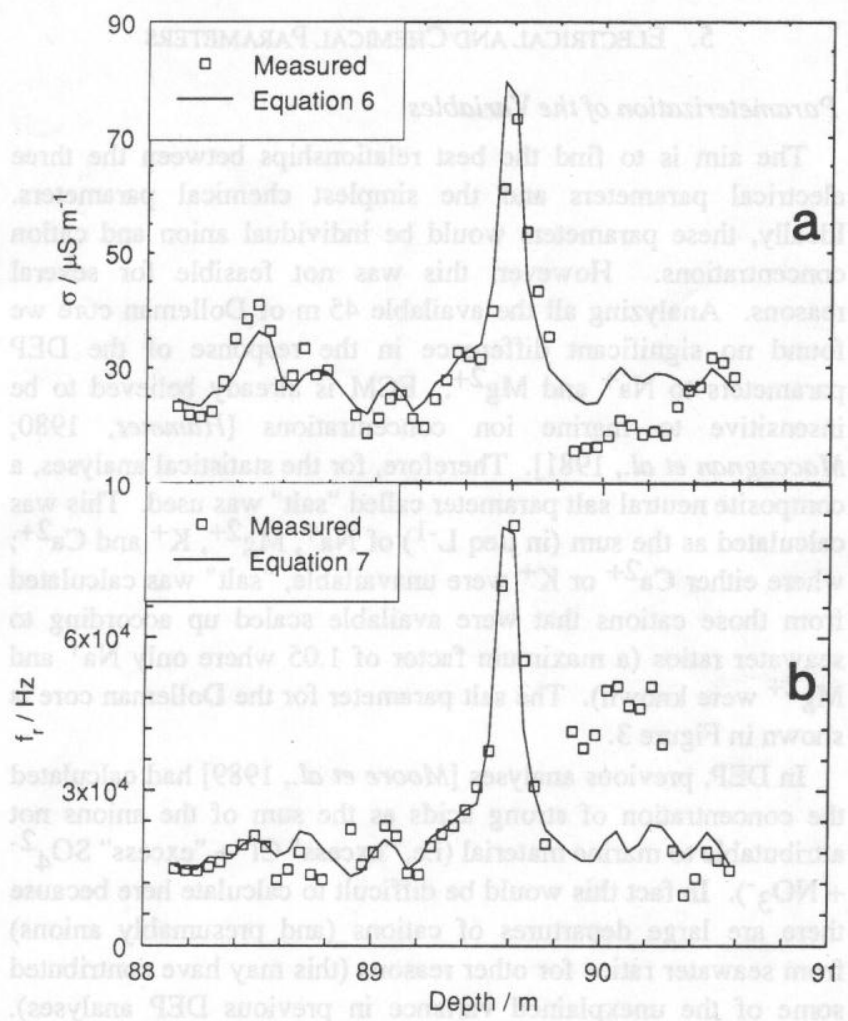

Fig. 7. DEP parameters for Dolleman Island, with the values calculated using equations (6) and (7): (a) $\sigma_{\infty}$ and $(b) f_{r}$.

It is possible to improve the fit of $\sigma_{\infty}$ in the upper part of the Dolleman core sections somewhat by altering the constants in equation (6), but there is no convincing reason at the moment to abandon a formula obtained from a far larger data set. It would in future be useful to refine the formula using a direct measure of $\mathrm{H}^{+}$throughout.

The Site G core is only the second core on which a DEP/chemistry comparison has been made. Because the acid peak is dominant, and salt concentrations are relatively low, it was not possible to extract any information on the salt dependence of the DEP parameters from this core. Both $\sigma_{\infty}$ and $f_{r}$ follow ECM current and $\mathrm{H}^{+}$closely (Figure 4). Both $\sigma_{\infty}$ and $f_{r}$ against $\mathrm{H}^{+}$look rather linear, with best fits of

$$
\begin{gathered}
\sigma_{\infty}=6.1( \pm 0.6)+1.83( \pm 0.08) \mathrm{H}^{+} \\
f_{r}=3700( \pm 700)+2000( \pm 100) \mathrm{H}^{+}
\end{gathered}
$$

The $\sigma_{\infty}$ dependence on $\mathrm{H}^{+}$for Site $\mathrm{G}$ in equation (8) (Figure 8 ) is quite similar to that for Dolleman Island in equation (6). The constant in equation (8) is lower than that for Dolleman Island, but similar to that $\left(4.5 \mu \mathrm{S} \mathrm{m}^{-1}\right)$ found for pure ice monocrystals at $-22^{\circ} \mathrm{C}$ [Camplin et al., 1978]. That figure is what we might expect for the constant if all factors contributing to $\sigma_{\infty}$ are present in equations (6) and (8). The larger value in equation (6) may imply that another factor (chemical or otherwise) is relevant for Dolleman Island ice. One possibility could be simply that the pooled "salt" and "acid" parameters are not an adequate description of the complex chemistry at Dolleman Island. This would be the case if there was a varying response to different salt cations, or to different acid counter ions.

The relationships for $f_{r}$ in equations (7) and (9) are quite different. The $f_{r}$ response in the Greenland core is very similar to that of $\sigma_{\infty}$ (see Figure 4), while in the Dolleman core $f_{r}$ behaves in a distinctly different fashion from $\sigma_{\infty}$. This difference is 


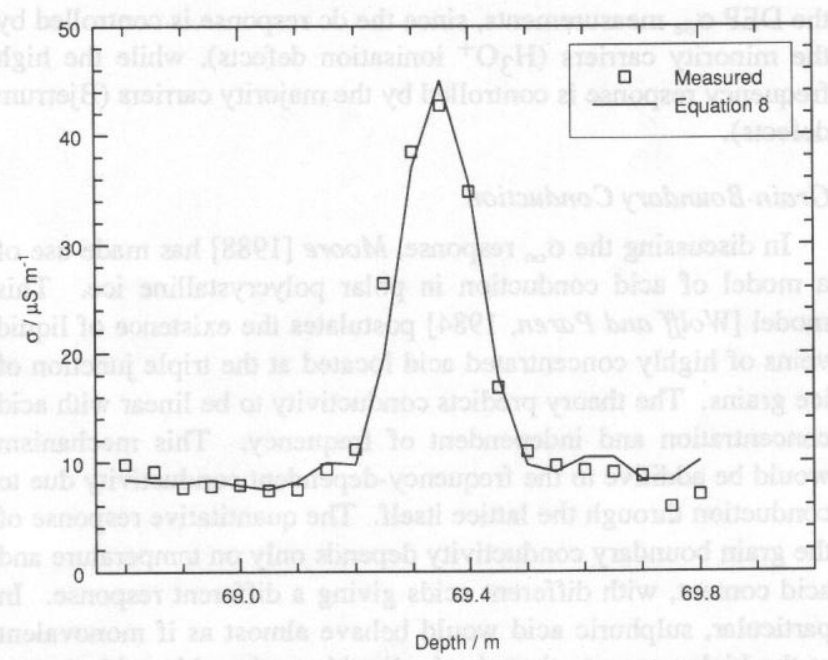

Fig. 8. The $\sigma_{\infty}$ relationship for Site G. The line is that of equation (8).

probably a result of the difference in the dielectric spectra (the frequency response of capacitance and conductance at each measurement position [Moore and Paren, 1987]) between the two sites. As may be expected from the simple chemistry of the Greenland Site $\mathrm{G}$ core, the dielectric spectra are very simple in comparison to those seen in the Dolleman ice. This simplicity apparently reduces the number of independent variables, defined by the ice characteristics, that are needed to describe the spectra, from two in the Dolleman core to only one in the Greenland Site $\mathrm{G}$ core. The shape of the dielectric spectra can therefore contain useful information on the chemical composition of the ice and the $f_{r}$ parameter was a convenient way of extracting this information from the Dolleman core. In the Greenland Site G core the spectra are simple and dependent only on the acid content of the core, and no useful information was contained in $f_{r}$.

\section{ECM AND DEP CONDUCTIVITY RESPONSE}

It is interesting to compare the response of DEP $\sigma_{\infty}$ and ECM I. The former is a measure of high-frequency conductivity, while the latter may be taken as a measure of dc conductivity [Schwander et al., 1983]. The measurements here have shown rather clearly that there is no dc current when there is no acid present in the ice, even when very high concentrations of other impurities are present. This also shows that ionization of ice by the high electric field strengths of over $1 \mathrm{kV} \mathrm{cm}-1$ is not a significant effect in ECM. Assuming this result holds for other samples, then the parts of $\sigma_{\infty}$ that are related to salt concentrations and the "constant" part must be purely a highfrequency feature.

The "acid" part of $\sigma_{\infty}$ must include the dc component identified by ECM, but may contain an additional high-frequency part. An estimate [Moore, 1988], made from the ECM current, of the dc conductivity $\sigma_{0}$ suggests that at typical $\mathrm{H}^{+}$concentrations, the ratio of $\sigma_{0}$ to the acid part of $\sigma_{\infty}$ is about 0.4-1.0 (lower values at higher acidities) at Dolleman Island. There is a major discrepancy in the nature of the response given by ECM $I$ and $\sigma_{\infty}$. ECM has a nonlinear response (response of $I$ reducing at higher $\mathrm{H}^{+}$) which may vary from core to core depending on the site itself or perhaps on the core storage temperature history and environment. On the basis of the two cores studied here, $\sigma_{\infty}$ seems to give a rather consistent linear response. We need to reconcile these two observations.

There are a number of possible reasons for the nonlinearity of the ECM response to acid. First, the geometry of the electrodes is not well-defined, as it is in DEP. However, Schwander at al. [1983] report empirical studies on the conductivity-current relationship using salt solutions that suggest that it is linear. A nonlinear current response therefore implies a nonlinear conductivity response.

There remain several other possible causes for the apparent nonlinearity of the response of $I$ to acid, and for the fact that different cores now appear to have different formulae. The explanations fall into three categories: those relating to the method, those relating to the chemistry, and those (discussed in section 7) that are based on the conduction mechanism in ice itself.

\section{Method}

The ECM method itself could give rise to a nonlinear response because of an incomplete chart recorder response to fast changes (oscilloscope pictures show that this is not crucial), because of changes (such as annealing) brought about by the varying temperature histories of the cores, or because of space-charge polarizations (SCP). SCP are associated with the decrease in current flow in ice if the electrodes are left stationary. The depletion of charge carriers at one electrode and their accumulation at the other lowers the current. The dependence of SCP on chemistry has not been studied, but we might expect nonlinear response with a greater effect at higher conductivities. Annealing may be important particularly when calibration curves vary on cores from the same site. Finally, if the ECM current is partly influenced by chemistry more than a few $\mathrm{mm}$ from the electrodes, this could affect the calibration curve, but it is unlikely that this is a large effect.

\section{Chemistry}

The chemistry could give rise to a nonlinear response if acid associated with different counter anions gave different ECM responses. In particular, since sulphate is probably the dominant counter ion at high acidities, but it is less dominant at low acidities, an apparent nonlinearity would arise if acid associated with sulphate gave a lower ECM response than that associated with nitrate and chloride, as discussed above [Legrand et al., 1987]. However, as also discussed, the present data do not allow us to resolve this question.

A difference in electrical response to different acids could explain the nonlinear ECM response, though this effect should also be noticeable in the DEP $\sigma_{\infty}$ response (equation (8)), since the acid part of $\sigma_{\infty}$ is only a small factor higher than $\sigma_{0}$. In fact, because of the small number of points in the DEP calibration, the DEP response for Site $\mathbf{G}$ is strongly controlled by five high concentration points, and it is not clear that any curvature at low concentration would be apparent. For Dolleman, the multiple regression makes it hard to rule out a nonlinear response to acid. The smoothing involved in using the long DEP core lengths may also contribute to depressing any nonlinearity in the DEP response.

\section{Electrical CONDUCTION IN POLAR ICE}

Laboratory work on electrical conduction in ice has concentrated on pure ice, and on ice doped particularly with HF [Camplin et al., 1978] and $\mathrm{HCl}$ [Takei and Maeno, 1987]. It has been difficult from earlier work to deduce the magnitude or mechanism of the effect of adding a range of impurities to ice. However, it is now possible to see a little more clearly the 
processes that affect the electrical conduction of natural polar ice.

In polar ice, conduction at dc is almost entirely controlled by the concentration of strong acid in the ice. In the absence of strong acid, dc conduction is comparatively limited; a probable upper limit of $0.2 \mu \mathrm{S} \mathrm{m}^{-1}$ at $-20^{\circ} \mathrm{C}$ can be calculated from the ECM current. At higher frequencies, in addition to the dc component, there is a component that conducts in the absence of impurity (that may be equal to the pure ice conductivity in laboratory experiments), but the conductivity is also strongly dependent on the concentration of neutral salts; acids may also increase the conductivity above the dc value. There are two main theories of conduction in polar ice, one relevant to processes within the ice lattice, the other to grain boundaries. The electrical properties of natural polycrystalline ice should be essentially explained as the sum of contributions from grain interiors and grain boundaries. The relative importance of the contributions is discussed below.

\section{Intracrystalline Conduction}

The traditional explanation [Hammer, 1980, 1983; Neftel et al., 1985] of ECM has been in terms of the classic Jaccard [1959, 1964, 1965] theory of point defects. This theory was developed purely to model the behavior of single crystals with no grain boundary effects. At dc, the minority carriers (which in polar ice at these temperatures and concentrations are $\mathrm{H}_{3} \mathrm{O}^{+}$ionisation defects) control the magnitude of the dc conductivity, and we can interpret this as showing that acids are creating ionisation defects. At ac, the majority carriers (Bjerrum $\mathrm{L}$ and $\mathrm{D}$ defects) can relax and produce a dielectric conductivity. This would suggest that neutral salts create Bjerrum defects, but have a negligible effect on the ionisation defect concentration. The effect of the neutral salts on the creation of Bjerrum L defects is discussed elsewhere [Moore, 1988]. No quantitative estimates can be made of the coefficients expected for acid in this case in equations (6)-(9), since no laboratory data are available for the type and number of defects produced by sulphuric and nitric acids. However, based on conductivity data from ice doped with HF (which is expected to be the easiest acid to introduce to the lattice), it seems that the amount of acid present in polar ice is too low to explain the magnitude of the dc conductivity by this mechanism [Wolff and Paren, 1984]. In comparing polar ice with artificial laboratorydoped ice it is important to remember that the incorporation method (from aerosol or solution) may be important, so that laboratory experiments cannot be easily applied to natural ice. It is possible that the identity of the counter anion might influence the ability of acid to be introduced into the lattice, thus contributing to nonlinearity through the chemical explanation of section 6.

Jaccard theory predicts that ionic defect concentrations (which determine the conductivity at dc) can be proportional to the square root of concentrations of impurities such as HF at higher concentrations. In laboratory experiments, a parabolic conductivity-concentration dependence was reported for $\mathrm{HF}$ and $\mathrm{HCl}$ doped ice at $-20^{\circ} \mathrm{C}$ [Camplin et al., 1978; Gross et al., 1978]. It is not clear how the different relationship of higher power exhibited by central Greenland cores fits into this mechanism. In addition, there are no laboratory data on ice doped with $\mathrm{H}_{2} \mathrm{SO}_{4}$ or $\mathrm{HNO}_{3}$ because of the great difficulty of growing crystals with measurable amounts of the large anions. Moore [1988] presents evidence that $\mathrm{Cl}^{-}$may be largely incorporated into the lattice, but it is unlikely that this is the case for the larger anions. Nonetheless, the Jaccard point defect model could explain the difference in response between the dc ECM measurements and the DEP $\sigma_{\infty}$ measurements, since the dc response is controlled by the minority carriers $\left(\mathrm{H}_{3} \mathrm{O}^{+}\right.$ionisation defects), while the high frequency response is controlled by the majority carriers (Bjerrum defects).

\section{Grain-Boundary Conduction}

In discussing the $\sigma_{\infty}$ response, Moore [1988] has made use of a model of acid conduction in polar polycrystalline ice. This model [Wolff and Paren, 1984] postulates the existence of liquid veins of highly concentrated acid located at the triple junction of ice grains. The theory predicts conductivity to be linear with acid concentration and independent of frequency. This mechanism would be additive to the frequency-dependent conductivity due to conduction through the lattice itself. The quantitative response of the grain boundary conductivity depends only on temperature and acid content, with different acids giving a different response. In particular, sulphuric acid would behave almost as if monovalent at the high concentrations in the liquid, so that this acid gives a lower response than do nitric or hydrochloric acids. In this model, the acids contribute mainly to the grain boundary mechanism, while neutral salts contribute to conduction through the grain by creation of Bjerrum defects, as in Jaccard's model.

The theory has received some support from direct observations in a scanning electron microscope of high concentrations of sulphur at triple junctions in some samples from Dolleman Island [Mulvaney et al., 1988; Wolff et al., 1988] and more rc.ently from Site G [Wolff and Mulvaney, 1990], although these observations cannot rule out the possibility that much acid remains in the grain also. Extrapolating laboratory measurements of the conductivity of highly concentrated acids to $-22^{\circ} \mathrm{C}$, Wolff and Paren [1984] predict a constant of proportionality between bulk ice conductivity $\left(\mu \mathrm{S} \mathrm{m}^{-1}\right)$ and acid concentration $\left(\mu \mathrm{eq} \mathrm{L}^{-1}\right)$ of 1.4 for $\mathrm{H}_{2} \mathrm{SO}_{4}, 2.4$ for $\mathrm{HCl}$, and 2.3 for $\mathrm{HNO}_{3}$. This difference in behavior between acids is consistent with the chemical explanation for the nonlinear conductivity response discussed in section 6. Comparing the proportionality factors of the acids to those in equations (6) and (8), the values are close to those predicted for $\mathrm{H}_{2} \mathrm{SO}_{4}$. The activation energy predicted by the model is $0.27 \mathrm{eV}$, close to that found for $\sigma_{\infty}$ between $-9^{\circ} \mathrm{C}$ and $22^{\circ} \mathrm{C}$ [Moore, 1988] and to that reported for ECM current [Schwander et al., 1983; Legrand et al., 1987]. However, the activation energy for ECM $I$ could also be accommodated in intracrystalline conduction as the energy needed to break a hydrogen bond.

There are a few observations that seem to contradict the Wolff and Paren [1984] model of acids localized at grain boundaries.

1. Two identical samples were taken from the annual layer of the Laki eruption in a Greenland ice core. One sample was allowed to heat up to $0^{\circ} \mathrm{C}$. The individual grains in the sample were peeled apart and about $50 \%$ of the sample was allowed to melt. The meltwater was removed and the remaining part of the ice grains were melted. The other sample was simply melted in its entirety. The $p \mathrm{H}$ of the two samples was measured. The first sample had a $p \mathrm{H}$ of 4.59 , while the second sample had a $p \mathrm{H}$ of 4.58. Assuming that each of grains melted from the outside inwards, this is difficult to reconcile with the model.

2. In the deep part of the Byrd core from Antarctica, crystal sizes up to $10 \mathrm{~cm}$ are frequently found [Gow and Williamson, 1976]. The ECM currents show no substantial difference whether both electrodes are placed at the grain boundary or outside.

Recrystallization of the ice over long time periods results in larger crystals containing fewer lattice imperfections. This presumably means there is less capacity within the grain for 
impurities. Both the SEM observations of sulphur at triple grain junctions and the contradictory evidence from the crystal washing experiment were done on young ice. The large grains from the Byrd core were much older and have undergone complete recrystallization many times. It is likely that there is a finite concentration of any impurity that can be accommodated within the lattice, rather than being excluded. Thus in ice with low acid concentrations there may be no acid at the triple junctions. This could lead to discontinuous liquid veins that would not conduct at dc, but would give a response at ac.

Grain-boundary conductivity gives very good quantitative agreement with measurements of dc conductivity and of the acid part of $\sigma_{\infty}$, and is supported by SEM evidence showing that there is certainly material at grain boundaries in some samples. On the other hand, it cannot easily explain the nonlinear ECM response to acidity or the contradictory evidence implying acid distributed through the grain described above. Jaccard theory can explain the nonlinearity, but not the higher power response seen in some cores, and cannot convincingly account for the magnitude of the dc conductivity of ice. The relative importance of intracrystalline and grain-boundary conduction is not yet clear, and further experiments that explore the relationship between electrical properties and very specific impurities will be needed before more progress can be made.

\section{ACID AND SAlt CONCENTRATION PREDICTION}

It has already been shown that ECM can be used to predict $\mathrm{H}^{+}$ concentration. The DEP parameters can be used to predict a total "salt + acid" [Moore et al., 1989] at least for the Dolleman core. Because of its high resolution and specificity for acid, ECM is generally more useful than DEP for predicting acid alone. If the two methods are used together, it should be possible to use ECM to derive acid concentration, and then use this in the DEP equations to derive salt concentration. This is best done through equations (6) and (7), rather than through the "acid + salt" parameter discussed by Moore et al., [1989], since this latter is a nonlinear relationship that may be dependent on the core used. Using equations (6) and (7), we can derive two equations for salt:

$$
\begin{gathered}
\text { Salt }=2.56 \sigma_{\infty}-3.66 \mathrm{H}^{+}-32.6 \\
\text { Salt }=0.00227 f_{r}-1.39 \mathrm{H}^{+}-18.6
\end{gathered}
$$

Because of the inconsistency of the $f_{r}$ parameter from core to core, equation (10) may be the most useful predictor. In an ideal situation, a pilot study would establish the best ECM and DEP calibrations for a particular core before predictive equations were used for later analyses. In this case, for the Dolleman Island core sections, we use equation (1) to predict $\mathrm{H}^{+}$(Figure 6) and equation (10) to predict salt (Figure 9). Note that electrical data alone have been used as the input here. Except in the lower section of the core (already described as anomalous), the prediction is quite good, and it seems that the two methods together can be a useful stratigraphic tool for neutral salt as well as acid prediction. The constant term in equation (10) may be too high: if the correct value in equation (6) is closer to the pure ice value of $4.5 \mu \mathrm{S} \mathrm{m}^{-1}$, as suggested by equation (8) found for the Site $\mathrm{G}$ data, then the constant in equation (10) would be closer to 11.5.

The salt prediction is less good at low concentrations, but because the calibrations and the subtraction of $\mathrm{H}^{+}$are dominated by high concentrations, this is only to be expected. Further work is needed to see how well the methods can be used to predict salt at more typical polar ice concentrations.

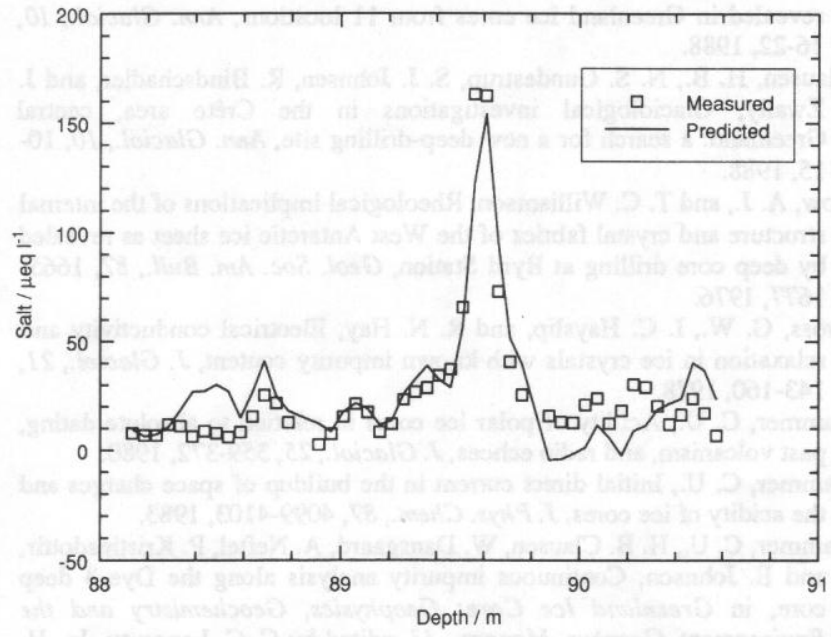

Fig. 9. Salt concentration at Dolleman Island, with the prediction based on equations (1) and (10) using only electrical data as input.

\section{CONCLUSION}

This work has shown clearly that two stratigraphic methods, a $\mathrm{dc}$ one (ECM) and one using many frequencies (DEP) can be used together, and are giving different information about ice core chemistry. ECM is responding to, and hence predicting, acid concentrations only, while DEP responds to acid and salt concentrations. This is a very clear differentiation, with no ECM response even in vast excess of salt. It has implications for conduction mechanisms in ice, and these need further exploration on ice with a range of impurity contents.

The most important conclusion for operational use is that the two methods together can be used to predict both acid and neutral salt down a core. In core with high acid concentration and low salt, such as Site G, the two methods give equivalent information. ECM would be the method of choice for acid alone, due to its high resolution and specificity (although DEP has the advantage of being totally nondestructive). In cores with high salt concentrations, the two methods together can accurately predict salt concentrations. It is not clear yet how much salt information can be derived in more normal Holocene Antarctic and Greenland cores, with 1-2 $\mu \mathrm{M}$ of acid and a similar amount of salt. This must be tested on further cores. However, the potential of the two methods together in Wisconsin age ice from Greenland is very exciting. In these cores, the acid is neutralised by large amounts of alkali dust, and the ECM signal dies completely in large parts of the ice. Although the response of DEP to alkali material is not yet known, we would expect that DEP will still be giving a strong signal in this ice, which contains high concentrations of sea salt and of alkali material [Hammer et al., 1985]. It should therefore prove a very useful tool for finding interesting parts of Wisconsin sections of core before chemical analysis is carried out.

Acknowledgments. J.C.M. and E.W.W. would like to thank the Geophysical Isotope Laboratory of the University of Copenhagen for travel funds to Copenhagen, G.W. Gross for useful comments on the manuscript, and A.P. Reid for carying out ion-chromatographic analyses in Cambridge. Part of the Danish contribution was funded by the Danish Natural Science Research Council.

\section{REFERENCES}

Camplin, G. C., J. W. Glen, and J. G. Paren, Theoretical models for interpreting the dielectric behavior of HF-doped ice, J. Glaciol., 21, 123-142, 1978.

Clausen, H. B., and C. U. Hammer, The Laki and Tambora eruptions as 
revealed in Greenland ice cores from 11 locations, Ann. Glaciol., 10, 16-22, 1988.

Clausen, H. B., N. S. Gundestrup, S. J. Johnsen, R. Bindschadler, and J. Zwally, Glaciological investigations in the Crête area, central Greenland: a search for a new deep-drilling site, Ann. Glaciol., 10, 10$15,1988$.

Gow, A. J., and T. C. Williamson, Rheological implications of the internal structure and crystal fabrics of the West Antarctic ice sheet as revealed by deep core drilling at Byrd Station, Geol. Soc. Am. Bull., 87, 1665 $1677,1976$.

Gross, G. W., I. C. Hayslip, and R. N. Hay, Electrical conductivity and relaxation in ice crystals with known impurity content, J. Glaciol., 21, 143-160, 1978.

Hammer, C. U., Acidity of polar ice cores in relation to absolute dating, past volcanism, and radio echoes, J. Glaciol., 25, 359-372, 1980.

Hammer, C. U., Initial direct current in the buildup of space charges and the acidity of ice cores, J.Phys. Chem., 87, 4099-4103, 1983.

Hammer, C. U., H. B. Clausen, W. Dansgaard, A. Neftel, P. Kristinsdottir, and E. Johnson, Continuous impurity analysis along the Dye 3 deep core, in Greenland Ice Core: Geophysics, Geochemistry and the Environment, Geophys. Monogr., 33, edited by C. C. Langway, Jr., H. Oeschger, and W. Dansgaard, pp. 90-94, AGU, Washington, D. C., 1985.

Hobbs, P. V., Ice Physics, Clarendon Press, Oxford, 1974.

Jaccard, C., Étude théoretique et experimentale des propriétés électriques de la glace, Helv. Phys. Acta, 32, 89-128, 1959.

Jaccard, C., Thermodynamics of irreversible processes applied to ice, Phys. Condens. Matter, 3, 99-118, 1964.

Jaccard, C., Mechanism of electrical conductivity in ice, Ann. N.Y. Acad. Sci., 125, 390-400, 1965.

Legrand, M. R., and R. J. Delmas, The ionic balance of Antarctic snow: a 10-year detailed record, Atmos. Environ., 18, 1867-1874, 1984.

Legrand, M. R., A. J. Aristarain, and R. J. Delmas, Acid titration of polar snow, Anal. Chem., 54, 1336-1339, 1982.

Legrand, M. R, J. R. Petit, and Y. S. Korotkevich, D.C. conductivity of Antarctic ice in relation to its chemistry, J. Phys., 48, C1/605-C1/611, 1987.

Maccagnan, M., J. M. Barnola, R. Delmas, and P. Duval, Static electrical conductivity as an indicator of the sulfate content of polar ice cores, Geophys. Res. Lett., 8, 970-972, 1981.

Moore, J. C., Geophysical aspects of ice core drilling in Antarctica, Ph.D. thesis, Council for National Academic Awards, U.K., 1988. (Also available as Publication DX 85333, U.M.I. Dissertation Information Service, Ann Arbor, Michigan.)

Moore, J. C., and J. G. Paren, A new technique for dielectric logging of Antarctic ice cores, J. Phys., 48, C1/155-C1/160, 1987.

Moore, J. C., R. Mulvaney, and J. G. Paren, Dielectric stratigraphy of ice: a new technique for determining total ionic concentrations in polar ice cores, Geophys. Res. Lett., 16, 1177-1180, 1989.

Mulvaney, R., and D. A. Peel, Anions and cations in ice cores from Dolleman Island and the Palmer Land plateau, Antarctic Peninsula, Ann. Glaciol., 10, 121-125, 1988.

Mulvaney, R., E. W. Wolff, and K. Oates, Sulphuric acid at grain boundaries in Antarctic ice, Nature, 331, 247-249, 1988.

Neftel, A., M. Andree, J. Schwander, B. Stauffer, and C. U. Hammer, Measurements of a kind of dc-conductivity on cores from Dye 3, in Greenland Ice Core: Geophysics, Geochemistry, and the Environment, Geophys. Monogr., 33, edited by C. C. Langway, Jr., H. Oeschger, and W. Dansgaard, pp. 32-38, AGU Washington, D. C., 1985.

Schwander, J., A. Neftel, H. Oeschger, and B. Stauffer, Measurement of direct current conductivity on ice samples for climatological applications, J. Phys. Chem., 87, 4157-4160, 1983.

Takei, I., and N. Maeno, Electrical characteristics of point defects in $\mathrm{HC}$ doped ice, J.Phys., 48, C1/121-C1/126, 1987.

Wolff, E., and R. Mulvaney, Impurity distributions in ice under different environmental conditions (abstract), Ann. Glaciol., 14, 362, 1990.

Wolff, E. W., and J. G. Paren, A two-phase model of electrical conduction in polar ice sheets, J. Geophys. Res., 89, 9433-9438, 1984.

Wolff, E. W., R. Mulvaney, and K. Oates, The location of impurities in Antarctic ice, Ann. Glaciol., 11, 194-197, 1988.

Zanolini, F., Conductimetrie et chimie de la glace à D57 (Terre Adélie) Application à la recherche du paléovolcanisme, Bull. Pirpsev 76, Cent. Natl. de la Rech. Sci./Inst. Natl. d'Astron. et de Geophys., Verrières-leBuisson, France, 1983.

J. C. Moore and E. W. Wolff, British Antarctic Survey, Natural Environment Research Council, High Cross, Madingley Road, Cambridge, CB3 OET, United Kingdom.

H. Clausen and C. U. Hammer, Department of Glaciology, Geophysical Isotope Laboratory, University of Copenhagen, Haraldsgade 6. Copenhagen 2200N, Denmark.

(Received July 9 1991;

revised October 23 1991;

accepted October 29 1991.) 